\title{
Craniofacial surgery and the humanities
}

\author{
Soon Man Kwon \\ Eastman Orthodontic Clinic, Seoul, Korea
}

Earlier this year, as I turned 60, I looked back and wondered why some people undergo burnout, both in their lives and in their studies. Then, the words of a mentor who taught me about the Book of Changes, which represents the basis of all Asian philosophies, came to my mind: Positivity at its fullness tilts towards negativity, while negativity at its extreme tilts back towards positivity. In other words, out of necessity emerges a solution. At first, I could not fully comprehend the true meaning of this statement, but as time passed, it gradually started to resonate with me more strongly. When one follows a successful path in life, and ultimately reaches the apex, the only remaining route is a descending one. Therefore, instead of self-righteously struggling to stay at the top and eventually collapsing, it is wise to prepare oneself for life's descending journey. Furthermore, a fruitful life calls for sincere devotion to prepare for overcoming the hardships that one encounters and for enthusiasm to take the next step forward. The world is constantly changing, and the nature of such changes is explicated in the Book of Changes. This is the main message of the book and the foundation for all Asian philosophies.

A few years ago, I had the opportunity to review application documents for medical schools in the United States, and I noticed that the entire process places a strong emphasis on applicants' preparedness in the humanities, as well as in the sciences. That is, in the United States, medicine is considered to be a field that integrates perspectives from the sciences and the humanities.

Is it just me, after working in the field of craniofacial surgery for over 25 years, who can easily sense a strong hint of the hu- manities in this field? Following an invitation to a study group through a friend's recommendation, I have spent every Monday night enjoying 2-hour lectures on Asian humanities for the past 18 years. This study group has become one of the most valuable parts of my life, and it has enriched me tremendously.

I often think about the field of plastic surgery with the eyes of an orthodontist who specializes in treating patients with craniofacial defects. During my training in the United States, I met multiple craniofacial surgeons who treated diseases like Crouzon syndrome and Apert syndrome, entering the media spotlight as they represented either their entire hospitals or at least the department of plastic surgery. These experiences led me to realize that craniofacial surgery embodies the essence of plastic surgery and truly represents a field that is concerned with the entire human body. But where are we now? The recent social tendency to undervalue the field of craniofacial surgery, while praising the field of aesthetic surgery, disheartens me a bit. I end this note by expressing my positive expectations for the day when our continuous striving for excellence and determination to achieve success will finally place our field of craniofacial surgery at the apex of plastic surgery and our profession will receive the highest regard from society.

\section{NOTE}

\section{Conflict of interest}

No potential conflict of interest relevant to this article was reported.

\footnotetext{
Correspondence: Soon Man Kwon

Eastman Orthodontic Clinic, 168 Apgujeong-ro, Gangnam-gu, Seoul 06030, Korea

E-mail: smkwon59@nate.com

Received April 15, 2019 / Accepted April 20, 2019
}

Copyright $\odot 2019$ The Korean Cleft Palate-Craniofacial Association 